\title{
ORGANIZAÇÃO DA EDUCAÇÃO NACIONAL: SISTEMA E CONSELHO NACIONAL DE EDUCAÇÃO, PLANO E FÓRUM NACIONAL DE EDUCAÇÃO
}

\author{
DermeVal SAVIANI
}

RESUMO: Este artigo analisa a organização da educação nacional a partir da forma como está disposta na atual LDB, indicando os elementos para a implantação do Sistema Nacional de Educação com sua instância normativa e deliberativa representada pelo Conselho Nacional de Educação, em articulação com o Plano Nacional de Educação e com seu órgão de acompanhamento e avaliação constituído pelo Fórum Nacional de Educação.

Palavras-chave: Organização da educação nacional. Sistema Nacional de Educação. Conselho Nacional de Educação. Plano Nacional de Educação. Fórum Nacional de Educação.

\section{ORGANIZATION OF THE BRAZILIAN EDUCATION: NATIONAL EDUCATION COUNCIL AND SYSTEM, PLAN AND NATIONAL EDUCATION FORUM}

ABSTRACT: This paper analyses the organization of the Brazilian education as established by the current LDB (Law of Basic Tenets and Guidelines of Brazilian Education), which points out elements to implement the National Education System with its normative and deliberative body, the National Education Council, in line with the National Education Plan, and its monitoring agency, the National Education Forum.

Key words: National education organization. National Education System. National Education Council. National Plan for Education. National Education Forum.

Doutor em Educação e professor emérito da Faculdade de Educação da Universidade Estadual de Campinas (UNICAMP). E-mail: dsaviani@yahoo.com.br 
A organização da educação nacional na LDB e a elisão do Sistema Nacional de Educação

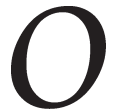

título IV da Lei de Diretrizes e Bases (LDB), "Da Organização da Educação Nacional", tinha, no projeto original, a denominação "Do Sistema Nacional de Educação". Essa expressão, mantida no Substitutivo Jorge Hage, acabou sendo retirada quando da aprovação do projeto na Câmara, não figurando também no texto da lei. No entanto, é, com certeza, um aspecto crucial, podendo mesmo ser considerada a questão central da LDB.

Com efeito, não há como ignorar a constatação de que a exigência de se fixar as diretrizes e bases da educação nacional implica diretamente o Sistema Nacional de Educação. E este é um enunciado que pode ser demonstrado histórica e logicamente.

Historicamente, a emergência dos Estados nacionais no decorrer do século XIX foi acompanhada da implantação dos sistemas nacionais de ensino nos diferentes países, como via para a erradicação do analfabetismo e universalização da instrução popular. O Brasil foi retardando essa iniciativa e, com isso, foi acumulando um déficit histórico imenso no campo educacional, em contraste com os países que instalaram os respectivos sistemas nacionais de ensino tanto na Europa e América do Norte quanto na América Latina, como ilustram os casos da Argentina, Chile e Uruguai.

O Brasil ainda esperaria a década de 1930 para que o problema começasse a ser formulado com maior clareza. O tema já aparece no "Manifesto dos Pioneiros da Educação Nova" de 1932 e, a partir da Constituição de 1934, a competência da União para legislar sobre as diretrizes da educação nacional marcou presença na viga mestra da nossa ordenação jurídica, a indicar a necessidade de normas comuns válidas para toda a nação, orientando a organização da educação em todo o país na forma de sistema.

Consequentemente, do ponto de vista histórico, a ideia de lei nacional de educação esteve sempre associada à implantação do Sistema Nacional de Educação, como demonstra a experiência da maioria dos países nos últimos dois séculos.

Do ponto de vista lógico, parece evidente a relação de implicação entre os conceitos de "lei de diretrizes e bases da educação nacional" e de 
"sistema nacional de educação". Quando a Constituição determina que a União estabeleça as diretrizes e bases da educação nacional, obviamente ela está pretendendo com isso que a educação, em todo o território do país, seja organizada segundo diretrizes comuns e sobre bases também comuns. E a organização educacional com essas características é o que se chama "Sistema Nacional de Educação".

O fato de que, por se tratar de uma República federativa, a Constituição reconheça também a competência dos Estados para legislar em matéria de educação em nada afeta o enunciado anterior. Com efeito, sistema não é unidade da identidade, uma unidade monolítica, indiferenciada, mas unidade da diversidade, um todo que articula uma variedade de elementos que, ao se integrarem ao todo, nem por isso perdem a própria identidade. Ao contrário, participam do todo, integram o sistema, na forma das respectivas especificidades. Em outros termos: uma unidade monolítica é tão avessa à ideia de sistema como uma multiplicidade desarticulada. Em verdade, sistematizar significa reunir, ordenar, articular elementos como partes de um todo. E este, agora articulado, passa a ser o sistema.

Portanto, a construção de um Sistema Nacional de Educação nada tem de incompatível com o regime federativo, pois o que é a Federação senão a unidade de vários estados que, preservando suas respectivas identidades, se articulam para assegurar interesses e necessidades comuns? E não é exatamente por isso que a instância que representa e administra o que há de comum entre os vários entes federativos se chama, precisamente, União? Ora, assim sendo, a Federação postula, portanto, o sistema nacional que, no campo da educação, representa a união dos vários serviços educacionais que se desenvolvem no âmbito territorial dos diversos entes federativos que compõem a Federação.

Considerar, pois, como inconstitucional a inclusão do tema relativo ao Sistema Nacional de Educação na LDB é uma "contradictio in terminis”, é a própria contradição lógica. Isso porque a LDB implica o Sistema.

Há uma estreita relação entre a LDB e a sistematização da educação. A educação assistemática não é objeto de legislação específica. Veja-se, por exemplo, as questões referentes ao pátrio poder, às diversões públicas etc., que podem ser consideradas atividades educativas segundo o próprio conceito adotado no Título I da LDB de 1996. No 
entanto, tais questôes são reguladas pelo Código Civil. Quando se pensa numa lei específica para a educação, é porque se está visando a sua sistematização e não apenas a sua institucionalização. Antes de haver leis de educação, havia instituições educativas. Isso não implica, entretanto, a vinculação necessária da sistematização à legislação, ou seja: não é necessário que haja lei específica de educação para que haja educação sistematizada; esta poderá existir mesmo não existindo aquela. $\mathrm{O}$ que fica claro é a vinculação necessária da lei específica de educação à sistematização. Tal lei visará consolidar o sistema ou reformá-lo, caso exista; ou, então, instituí-lo, ou, pelo menos, determinar as condições para que ele seja criado, caso não exista.

Ora, em se tratando de uma lei que se propóe a fixar as diretrizes e bases da educação nacional, mais ainda se impõe a conclusão antes apresentada. Com efeito, se por diretrizes e bases se entendem fins e meios, ao serem estes definidos em termos nacionais, pretende-se não apenas indicar os rumos para onde se quer caminhar, mas organizar a forma, isto é, os meios através dos quais os fins serão atingidos. E a organização intencional dos meios, com vistas a se atingir os fins educacionais preconizados em âmbito nacional, é o que se chama "Sistema Nacional de Educação".

Não obstante essa evidência, na trajetória da nova LDB houve aqueles protagonistas que incidiram nessa "contradictio in terminis", opinando pela inconstitucionalidade do Título relativo ao Sistema Nacional de Educação que integrava o Substitutivo Jorge Hage. Em consequência, a referida denominação foi substituída por esta outra: Organização da Educação Nacional.

Em verdade, essa foi uma solução de tipo nominalista, já que os que a postularam se satisfizeram com a mudança do nome sem se preocuparem com a manutenção do mesmo conteúdo. O viés nominalista talvez tenha tido mesmo algum peso, ao menos formalmente, pois se argumentava que na Constituição não aparecia a expressão "Sistema Nacional de Educação", mas apenas "sistemas de ensino". Aos que defendiam o sistema nacional, em contrapartida, preocupava exatamente o seu conteúdo, secundarizando a denominação, o que permitiu, nas negociações, que se abrisse mão da expressão "Sistema Nacional de Educação".

Efetivamente, no projeto aprovado na Câmara, o Capítulo que tratava "Da Organização da Educação Nacional" preservava os mecanismos 
básicos do sistema, entre os quais desempenhava papel central o Conselho Nacional de Educação secundado pelo Fórum Nacional de Educação. Com a prevalência do Substitutivo Darcy Ribeiro manteve-se a denominação (Organização da Educação Nacional), mas o conteúdo foi fortemente alterado. O Título IV - Da Organização da Educação Nacional -, da LDB, está calcado no Substitutivo Darcy Ribeiro. Em consequência, desapareceu o Fórum Nacional de Educação.

O Conselho Nacional de Educação (CNE), que estava inteiramente ausente do primeiro projeto $\mathrm{D}$. Ribeiro, na versão final convertida em lei mereceu apenas uma menção no parágrafo primeiro do inciso IX do artigo $9^{\circ}$. E isso era inevitável, pois o CNE já havia sido criado por medida provisória originária do presidente Itamar Franco e reeditada por Fernando Henrique Cardoso, convertida pelo Congresso Nacional na Lei n. 9.131, de 24 de novembro de 1995 .

A razão invocada para a exclusão do CNE do texto da LDB foi a denominada "inconstitucionalidade por vício de iniciativa", argumentando-se com o artigo 84, VI ("compete privativamente ao Presidente da República dispor sobre a organização e o funcionamento da administração federal, na forma da lei") e Xxv ("prover e extinguir os cargos públicos federais, na forma da lei").

Entendo que a interpretação supra é discutível, pois parte do entendimento prévio do $\mathrm{CNE}$ como sendo meramente um órgão administrativo federal. Na concepção de LDB que prevaleceu na Câmara, o CNE tinha outro caráter: era uma instância com funçôes deliberativas no âmbito da educação, análogas àquelas exercidas pelo Legislativo e Judiciário no âmbito da sociedade como um todo.

Fica claro, no entanto, que não era esse, propriamente, o problema. Mesmo admitindo-se que estivesse configurado o "vício de iniciativa", o mesmo já teria sido sanado quando, por iniciativa do ministro da Educação Murílio Hingel, foi fechado o Conselho Federal de Educação (CFE) e instituído, por meio de medida provisória, o CNE.

A questão, aí, era o caráter deliberativo do CNE que, segundo a interpretação tanto do governo Collor como do governo Fernando Henrique Cardoso, secundarizaria o MEC na tarefa de formular a política nacional de educação. O que se pretendia, no entanto, era instituir uma instância com representação permanente da sociedade civil para compartilhar com o governo a formulação, acompanhamento e avaliação da 
política educacional. Tanto assim que, na versão aprovada pela Câmara, metade dos membros do CNE era escolhida pelo Presidente da República.

Deve-se destacar que, com esse encaminhamento, se pretendia evitar a descontinuidade que tem marcado a política educacional, o que conduz ao fracasso das tentativas de mudança, pois tudo volta à estaca zero a cada troca de equipe de governo. $\mathrm{Na}$ verdade, cada governante quer imprimir a própria marca, quer fazer a sua reforma. Com isso, interrompe o que havia sido iniciado na gestão anterior e a educação fica marcando passo, já que se trata de um assunto que só pode ser equacionado satisfatoriamente no médio e longo prazos, jamais no curto prazo. $\mathrm{E}$ as consequências recaem sobre a população, que vê indefinidamente adiado o atendimento de suas necessidades educacionais.

As atribuiçõoes de articulação, coordenação e avaliação enfeixadas no âmbito da União, vale dizer, do MEC, apesar das resistências de caráter "nominalista", implicam, de algum modo, a ideia de Sistema Nacional de Educação.

Enfim, o Titulo IV da LDB, denominado "Da Organização da Educação Nacional”, tem início com a reprodução do caput do artigo 211 da Constituição Federal, que estipula como tarefa da União, dos estados/Distrito Federal e dos municípios, a organização, em regime de colaboração, dos seus sistemas de ensino (art. $8^{\circ}$ ). Em seguida, são definidas as atribuições da Uniāo (art. 90), dos estados e do Distrito Federal (art. 10), dos municípios (art. 11), dos estabelecimentos de ensino (art. 12) e dos docentes (art. 13). Determina-se também a abrangência dos sistemas de ensino federal (art. 16), estaduais, do Distrito Federal (art. 17) e dos municípios (art. 18) e se conclui com a classificação das instituições de ensino em públicas e privadas (art. 19) e a especificação das categorias em que se enquadram as instituiçóes privadas de ensino (art. 20).

$\mathrm{Na}$ distribuição das competências entre as diversas instâncias de governo, a LDB atribui aos municípios a responsabilidade de manter a educação infantil, garantindo, com prioridade, o ensino fundamental. Aos estados cabe colaborar com os municípios na oferta de ensino fundamental e manter, com prioridade, o ensino médio. À União, no exercício da coordenação nacional da política de educação, compete prestar assistência técnica e financeira aos estados, Distrito Federal e municípios, 
estabelecer diretrizes curriculares e realizar a avaliação do rendimento escolar de todos os graus de ensino, além de manter as próprias instituições de ensino que, juntamente com as escolas superiores privadas, comporão o sistema federal de ensino. Dentre as atribuições da União destaca-se, para os propósitos deste texto, o disposto no inciso I do artigo 90: "elaborar o Plano Nacional de Educação, em colaboração com os Estados, o Distrito Federal e os Municípios”.

Cabe observar que, se o ensino fundamental é definido como prioridade dos municípios e o ensino médio, prioridade dos estados, quando são definidas as atribuições da União não consta a prioridade ao ensino superior e sequer há referência à responsabilidade da União de manter universidades ou instituições de nível superior. Tal omissão estaria sinalizando para uma possível política da União de se desfazer das universidades federais ou, pelo menos, não priorizar o ensino superior.

Mas a configuração da organização da educação nacional não se esgota no Título IV, que tem essa denominação. Dir-se-ia que aí se trata apenas do aspecto formal, isto é, define-se a forma da organização, destacando-se, por isso, os âmbitos de competência dos sujeitos (agentes) da referida organização. Já o aspecto material, isto é, o conteúdo (o objeto) da organização da educação nacional é definido nos títulos seguintes.

Com efeito, o Título V - Dos Níveis e das Modalidades de Educação e Ensino - dispõe sobre a Educação Básica (Cap. II) que compreende a Educação Infantil (Seção II), o Ensino Fundamental (Seção III), o Ensino Médio (Seção IV), e a Educação de Jovens e Adultos (Seção v). O mesmo Titulo V dispõe ainda sobre a Educação Profissional (Capítulo III), a Educação Superior (Cap. IV) e a Educação Especial (Cap. V). Na sequência, o Título VI trata dos Profissionais da Educação e o Título VII, dos Recursos Financeiros. Completando o arcabouço da organização da educação nacional, o Título VIII - Das Disposições Gerais - contém dispositivos relativos à Educação Indígena e à Educação a Distância.

\section{Sistema Nacional de Educação e Conselho Nacional de Educação}

A primeira oportunidade de organizarmos um Sistema Nacional de Educação no Brasil ocorreu na década de 1930 com o "Manifesto dos Pioneiros da Educação Nova” e com a Constituição Federal de 1934, que inscreveu a exigência de fixação, pela União, das diretrizes da educa- 
ção nacional e a formulação do Plano Nacional de Educação. Esta oportunidade foi perdida com o advento do Estado Novo.

Uma nova oportunidade se abriu em decorrência da Constituição Federal de 1946, que reiterou a exigência de fixação, por parte da União, das diretrizes e bases da educação nacional. Já no projeto original, a questão da organização do Sistema Nacional de Educação não foi assegurada à vista da assimilação, feita pelos próprios renovadores, do sistema nacional à tese da centralização do ensino. Prevalecendo a visão descentralizadora, o eixo do projeto de LDB foi posto nos sistemas estaduais, admitindo-se o sistema federal em caráter supletivo. $\mathrm{Na}$ sequência, os interesses das escolas particulares, capitaneados pela Igreja Católica e guiando-se pelo temor do suposto monopólio estatal do ensino, concorreram para afastar a preocupação com o Sistema Nacional de Educação.

Finalmente, a terceira oportunidade nos foi dada pela elaboração da nova Lei de Diretrizes e Bases da educação nacional, em decorrência da atual Constituição Federal, promulgada em 5 de outubro de 1988. Desta vez, a organização do Sistema Nacional de Educação foi inviabilizada pela interferência governamental, que preferiu uma LDB minimalista para não comprometer sua política educacional que promovia a desresponsabilização da União com a manutenção da educação, ao mesmo tempo em que concentrava em suas mãos o controle, por meio de um sistema nacional de avaliação do ensino em todos os seus níveis e modalidades.

Após três oportunidades perdidas, abriu-se, em 2010, uma nova possibilidade com a realização da Conferência Nacional de Educação (CONAE). Efetivamente, as conclusões e encaminhamentos aprovados nesta Conferência preveem a instituição no país de um Sistema Nacional de Educação. Mas, para que isso venha a ocorrer, é preciso que se garantam determinados requisitos.

Em primeiro lugar, trata-se de construir um verdadeiro sistema, isto é, um conjunto unificado que articula todos os aspectos da educação no país inteiro, com normas comuns válidas para todo o território nacional e com procedimentos também comuns, visando a assegurar educação com o mesmo padrão de qualidade a toda a população do país. Não se trata, portanto, de se entender o Sistema Nacional de Educação como um grande guarda-chuva com a mera função de abrigar 27 sistemas estaduais de ensino, incluído o do Distrito Federal, o próprio sistema 
federal de ensino e, no limite, 5.565 sistemas municipais de ensino, supostamente autônomos entre si. Se for aprovada uma proposta nesses termos, o Sistema Nacional de Educação se reduzirá a uma mera formalidade, mantendo-se, no fundamental, o quadro de hoje com todas as contradiçôes, desencontros, imprecisões e improvisações que marcam a situação atual, de fato avessa às exigências da organização da educação na forma de um sistema nacional.

Penso que o risco apontado se faz presente na proposta contida no documento-base da CONAE quando enuncia a construção de um sistema nacional articulado de educação, isto é, o sistema nacional teria a função de simples articulador dos sistemas estaduais e municipais de ensino. Isso não basta. É preciso instituir um sistema nacional em sentido próprio e que, portanto, não dependa das adesões autônomas e a posteriori de estados e municípios. Sua adesão ao sistema nacional deve decorrer da participação efetiva na sua construção, submetendo-se, em consequência, às suas regras. Não se trata, pois, de conferir a estados e municípios, a partir dos respectivos sistemas autônomos, a prerrogativa de aderir ou não a este ou àquele aspecto que caracteriza o sistema nacional.

Em segundo lugar, não se pode esquecer que o sistema só pode ser público. Portanto, não há que transigir com os direitos de educar dos particulares. As instituições privadas, em suas diferentes modalidades, integrarão o sistema precisamente como particulares. Deve-se entender que, quanto mais autenticamente particulares elas forem, melhor se tipifica sua contribuição própria para o desenvolvimento da educação brasileira. Portanto, não cabe travesti-las de públicas, seja pela transferência de recursos na forma de subsídios e isenções, seja pela transferência de poder, admitindo-as na gestão e operação do complexo das instituições públicas que integram o sistema.

Não se pode, também, enfraquecer o caráter público do Sistema Nacional de Educação com a consideração de que a educação é uma tarefa não apenas do governo, mas de toda a sociedade. De fato, não é uma tarefa de governo, mas de Estado. E é uma tarefa de toda a sociedade, na medida em que o Estado, como guardião do bem público, expressa, ou deveria expressar, os interesses de toda a sociedade, que deveria não apenas se sentir representada no Estado, mas vivenciá-lo como coisa sua. Nesses termos, a forma pela qual a sociedade, em seu conjunto, estará cuidando da educação é reforçando seu caráter público 
e cobrando do Estado a efetiva priorização da educação. Deve-se, portanto, fazer reverter a tendência, hoje em curso, de diluir as responsabilidades educativas do poder público, transferindo-as para iniciativas de filantropia e de voluntariado. Tal tendência configura um retrocesso diante das conquistas do Estado moderno, que superou o estágio inicial da modernidade, quando a questão da instrução popular era tratada como um problema de caridade pública. Essa fase foi ultrapassada pela tese da escola pública universal, gratuita, leiga e obrigatória concebida como direito de todos e dever do Estado.

As funções normativas e deliberativas do sistema serão exercidas pelo Conselho Nacional de Educação (CNE). Pensado como um órgão revestido das características de autonomia, representatividade e legitimidade, como uma instância permanente e renovada por critérios e periodicidade distintos daqueles que vigoram no âmbito da política partidária, o CNE estará, senão imune, pelo menos não tão vulnerável aos interesses da política miúda.

Em analogia com o campo político, essa instância exerce as funções correspondentes ao Legislativo e Judiciário, pois, além de baixar as normas de funcionamento do sistema, julga as eventuais pendências e decide, em última instância, sobre os recursos das instâncias inferiores. Assim sendo, trata-se de um órgão de Estado e não de governo. Deve, pois, como ocorre com os poderes Legislativo e Judiciário, gozar de autonomia financeira e administrativa, não podendo ficar, como hoje ocorre, na dependência total do Executivo. Como órgão de Estado, sua composição não deve ocorrer por representações das entidades sociais que, de alguma forma, se ligam à educação, o que acabaria por lhe conferir um caráter corporativo. Isso quer dizer que o critério de indicação dos membros do CNE deve ter por base as qualificaçóes decorrentes da experiência no campo da educação, independentemente de seu vínculo maior ou menor com este ou aquele tipo de instituição, assim como neste ou naquele nível ou modalidade de ensino.

$\mathrm{Na}$ construção do Sistema Nacional de Educação deve-se ter como referência o regime de colaboração entre a União, os estados, o Distrito Federal e os municípios, conforme disposto na Constituição Federal.

$\mathrm{Na}$ repartição das responsabilidades, os entes federativos concorrerão na medida de suas peculiaridades e de suas competências específicas consolidadas pela tradição e confirmadas pelo arcabouço jurídico. 
Assim, as normas básicas que regularão o funcionamento do sistema serão de responsabilidade da União, consubstanciadas na Lei de Diretrizes e Bases da Educação Nacional e no PNE, traduzidas e especificadas pelas medidas estabelecidas no âmbito do CNE. Os estados poderão expedir legislação complementar, adequando as normas gerais a eventuais particularidades locais.

O financiamento do sistema será compartilhado pelas três instâncias, conforme o regime dos fundos de desenvolvimento educacional. Assim, além do Fundo de Manutenção e Desenvolvimento da Educação Básica e de Valorização dos Profissionais da Educação (FUndeB), que deverá ser aperfeiçoado, cabe criar também um Fundo de Manutenção da Educação Superior (FUNDES). Se, no caso do FUNDEb, a maioria dos recursos provém de estados e municípios, cabendo à União um papel complementar, em relação ao FUNDES a responsabilidade da União será dominante, entrando os estados apenas em caráter complementar, limitando-se aos casos de experiência já consolidada na manutenção de universidades.

A formação de professores e a definição da carreira e condições de exercício docente constituem algo que dificilmente pode ser confiado aos municípios. Com efeito, a própria LDB, pelo inciso $\mathrm{V}$ do artigo 11, os impede de atuar na formação de professores, uma vez que poderão se dedicar a outros níveis de ensino ulteriores ao fundamental "somente quando estiverem atendidas plenamente as necessidades de sua área de competência e com recursos acima dos percentuais mínimos vinculados pela Constituição Federal à manutenção e desenvolvimento do ensino”. Uma vez que a formação de professores ocorre, como regra, no nível superior e, transitoriamente, no nível médio, essa atribuição escapa aos municípios. Segue-se que as questões relativas ao magistério constituem matéria de responsabilidade compartilhada entre União e estados.

A responsabilidade principal dos municípios incidirá sobre a construção e conservação dos prédios escolares e de seus equipamentos, assim como sobre a inspeção de suas condiçôes de funcionamento, além, é claro, dos serviços de apoio como merenda escolar, transporte escolar etc. Efetivamente, são esses os aspectos em que os municípios têm experiência consolidada. Estes, de modo geral, estão equipados para regular, por uma legislação própria, a ocupação e uso do solo. Rotineiramente, cabe às prefeituras examinar projetos relacionados aos mais variados tipos de 
construção, verificando sua adequação à finalidade da obra a ser construída. Assim, quer se trate de moradias, de hospitais, de restaurantes, de igrejas etc., o órgão municipal irá verificar se o projeto atende às características próprias do tipo de construção preconizado à luz da finalidade que lhe caberá cumprir. Ora, é evidente que, em se tratando das escolas, as prefeituras também podem cumprir, sem qualquer dificuldade, essa função. Obviamente, isso não impede que os municípios assumam, em caráter complementar e nos limites de suas possibilidades, responsabilidades específicas no campo educacional, mesmo no âmbito daquelas funçóes que cabem prioritariamente aos estados e à União.

Em suma, o Sistema Nacional de Educação integra e articula todos os níveis e modalidades de educação com todos os recursos e serviços que lhes correspondem, organizados e geridos, em regime de colaboração, por todos os entes federativos, sob coordenação da União. Fica claro, pois, que a repartição das atribuições não implica a exclusão da participação dos entes aos quais não cabe a responsabilidade direta pelo cumprimento daquela função. Eles participarão por meio dos respectivos colegiados, acompanhando e apresentando subsídios que venham a tornar mais qualificadas as decisões tomadas. E assumirão responsabilidades diretas nos aspectos que lhes correspondem, por meio das secretarias e conselhos estaduais de Educação e das secretarias e conselhos municipais de Educação, sempre que tal procedimento venha a concorrer para a flexibilização e maior eficácia da operação do Sistema Nacional de Educação, sem prejuízo, evidentemente, do comum padrão de qualidade que caracteriza o Sistema Nacional de Educação.

Por fim e com certeza o mais importante, deve-se considerar com todo cuidado o problema do conteúdo da educação a ser desenvolvido no âmbito de todo o sistema. Conforme os documentos legais, a começar pela Constituição Federal e LDB, a educação tem por finalidade o pleno desenvolvimento da pessoa, o preparo para o exercício da cidadania e a qualificação para o trabalho. Levando-se em conta que esses fins se referem indistintamente a todos os membros da sociedade brasileira considerados individualmente, podemos interpretar, com Gramsci (1975), que o objetivo da educação é conduzir cada indivíduo até a condição de ser capaz de dirigir e controlar quem dirige.

Fica claro que tal objetivo não poderá ser atingido com currículos que pretendam conferir competências para a realização das tarefas 
rotineiras demandadas pela estrutura ocupacional, concentrando-se apenas na qualificação profissional e secundarizando o desenvolvimento da pessoa e o preparo para a cidadania.

Diferentemente dessa tendência dominante, a organização curricular dos vários níveis e modalidades de ensino deverá tomar como referência a forma de organização da sociedade atual, assegurando sua plena compreensão por parte dos educandos. Isso significa que se deve promover a abertura da caixa-preta da chamada "sociedade do conhecimento". A educação a ser ministrada deverá garantir a todos o acesso aos fundamentos e pressupostos que tornaram possível a revolução microeletrônica, que é a base tanto dos processos de automação que operam no sistema produtivo como das tecnologias da informação que se movem nos ambientes virtuais da comunicação eletrônica.

Assim, além de tornar acessíveis os computadores e em vez de lançar a educação na esfera dos cursos a distância de forma açodada, é preciso garantir não apenas o domínio técnico-operativo dessas tecnologias, mas a compreensão dos princípios científicos e dos processos que as tornaram possíveis. Se continuarmos pelos caminhos que estamos trilhando, não parece exagerado considerar que estamos, de fato, realizando aquelas profecias dos textos de ficção científica que previram uma humanidade submetida ao jugo de suas próprias criaturas, sendo dirigida por máquinas engrenadas em processos automáticos. Pois não deixa de ser verdade que, cada vez mais, nos relacionamos com os computadores, considerando-os fetichisticamente como pessoas a cujos desígnios nós nos sujeitamos e, sem conseguirmos compreendê-los, atribuímos a eles determinadas características psicológicas traduzidas em expressóes que os técnicos utilizam para nos explicar seu comportamento, tais como: ele, o computador, não reagiu bem ao seu procedimento; ele é assim mesmo, às vezes aceita o que você propõe e às vezes não aceita etc.

Nas condições atuais, não é mais suficiente alertar contra os perigos da racionalidade técnica, advogando-se uma formação centrada numa cultura de base humanística voltada para a filosofia, literatura, artes e ciências humanas à revelia do desenvolvimento das chamadas "ciências duras”. É preciso operar um giro da formação na direção de uma cultura de base científica que articule, num complexo compreensivo, as ciências humano-naturais que estão modificando profundamente as formas de vida, passando-as pelo crivo da reflexão filosófica e da expressão artística e literária. É este o desafio que o Sistema Nacional de Educação 
terá de enfrentar. Somente assim será possível, além de qualificar para o trabalho, promover o pleno desenvolvimento da pessoa e o preparo para o exercício da cidadania.

\section{Plano Nacional de Educação e Fórum Nacional de Educação}

Há uma íntima relação entre os conceitos de "Sistema Nacional de Educação" e "Plano Nacional de Educação". Isso porque o sistema resulta da atividade sistematizada; e a ação sistematizada é aquela que busca intencionalmente realizar determinadas finalidades. É, pois, uma ação planejada. Sistema de ensino significa, assim, uma ordenação articulada dos vários elementos necessários à consecução dos objetivos educacionais preconizados para a população à qual se destina. Supõe, portanto, o planejamento. Ora, se "sistema é a unidade de vários elementos intencionalmente reunidos, de modo a formar um conjunto coerente e operante" (Saviani, 2008, p. 80), as exigências de intencionalidade e coerência implicam que o sistema se organize e opere segundo um plano. Consequentemente, há uma estreita relação entre sistema de educação e plano de educação. Se o desenvolvimento do Sistema Educacional é condicionado pelo Plano de Educação, no âmbito do qual se definem as metas e os recursos com os quais o Sistema opera, a viabilidade do Plano de Educação depende do Sistema Educacional, pois é nele e por ele que as metas previstas poderão se tornar realidade.

Podemos dizer que a formulação do Plano Nacional de Educação (PNE) se põe como uma exigência para que o Sistema Nacional de Educação mantenha permanentemente suas características próprias. Com efeito, é preciso atuar de modo sistematizado no sistema educacional; caso contrário, ele tenderá a distanciar-se dos objetivos humanos, caracterizando-se especificamente como estrutura (resultado coletivo não intencional de práxis intencionais individuais). Com isso, o funcionamento do sistema acaba caindo numa rotina em que as ações se tornam mecânicas, automáticas, rompendo-se o movimento dialético ação-reflexão-ação que é condição sine qua non da educação sistematizada e, portanto, da prática educativa própria do sistema educacional. Isso porque o modo de existência do homem é tal que uma práxis que se estrutura em função de determinado(s) objetivo(s) não se encerra com a sua realização, mas traz a exigência da realização de novos objetivos, projetandose numa nova práxis. 
Portanto, para que o sistema permaneça vivo e não degenere em simples estrutura, burocratizando-se, é necessário manter continuamente, em termos coletivos, a intencionalidade das ações. Isso significa que em nenhum momento se deve perder de vista o caráter racional das atividades desenvolvidas. E o plano educacional é exatamente o instrumento que visa introduzir racionalidade na prática educativa como condição para se superar o espontaneísmo e as improvisaçôes, que são o oposto da educação sistematizada e de sua organização na forma de sistema.

Historicamente, no Brasil, podemos identificar a origem da ideia de plano na educação em 1932, com o "Manifesto dos Pioneiros da Educação Nova" que, diagnosticando a educação no Brasil, detectou a falta de "unidade de plano" e formulou um "Plano de reconstrução educacional" (Manifesto, 1984, p. 407).

O conceito de plano, no "Manifesto", assume o sentido de instrumento de introdução da racionalidade científica no campo da educação, em consonância com o ideário escolanovista, para o qual "os trabalhos científicos no ramo da educação já nos faziam sentir, em toda a sua força reconstrutora, o axioma de que se pode ser tão científico no estudo e na resolução dos problemas educativos, como nos da engenharia e das finanças" (idem, ibid., p. 409).

A Constituição brasileira de 1934 estabeleceu como competência da União fixar o Plano Nacional de Educação a ser elaborado pelo Conselho Nacional de Educação.

Durante o período do Estado Novo (1937-1945), Capanema entendeu que "a promulgação de uma lei geral de ensino, ou seja, de um Código da Educação Nacional, apresentava-se como condição prévia para a elaboração de um plano de educação" (Horta, 1997, p. 149$150)$, que, por sua vez, se constituiria na "base e roteiro das providências de governo" no âmbito educacional.

A Lei de Diretrizes e Bases da Educação Nacional, de 1961, refere-se ao "plano de educação", no parágrafo $2^{\circ}$ do artigo 92, como instrumento de execução dos fundos do ensino primário, do ensino médio e do ensino superior.

Designado para relatar o Plano de Educação no CFE, Anísio Teixeira esclareceu o sentido do preceito legal e arquitetou um procedimento engenhoso para a distribuição dos recursos, detalhando-o no que se refere ao plano do Fundo Nacional do Ensino Primário. Foi este 
procedimento que inspirou a criação, em 1996, do Fundo de Manutenção e Desenvolvimento do Ensino Fundamental e de Valorização do Magistério (FUNDEF), orientação que foi mantida no FUNDEB, instituído em dezembro de 2006.

A partir de 1964, o protagonismo no planejamento educacional se transferiu dos educadores para os tecnocratas, o que se expressou na subordinação do Ministério da Educação (MEC) ao Ministério do Planejamento, cujos corpos dirigente e técnico eram, via de regra, oriundos da área de formação das ciências econômicas. Nesse contexto, os planos para a área de educação decorriam diretamente dos Planos Nacionais de Desenvolvimento (PND), recebendo, por isso mesmo, a denominação de "Planos Setoriais de Educação e Cultura" (PSEC).

Quanto ao PNE atualmente em vigor, ele resultou de duas propostas: uma elaborada pelo MEC, na gestão Paulo Renato do governo FHC, e outra gestada no II Congresso Nacional de Educação.

Em suma, na década de 1930, o conceito de plano assumiu o sentido de introdução da racionalidade científica na educação; no Estado Novo, metamorfoseou-se em instrumento destinado a revestir de racionalidade o controle político-ideológico exercido pela política educacional; com a LDB de 1961 se converteu em instrumento de viabilização da racionalidade distributiva dos recursos educacionais; no regime militar, caracterizou-se como instrumento de introdução da racionalidade tecnocrática na educação; na Nova República, sua marca foi o democratismo com o que a ideia de introduzir, pelo plano, uma espécie de racionalidade democrática se revestiu de ambiguidade; finalmente, na era FHC, o plano se transmutou em instrumento de introdução da racionalidade financeira na educação.

Considerando que o prazo de vigência do atual PNE se esgota em 9 de janeiro de 2011, será necessário encaminhar ao Congresso Nacional o projeto do novo plano. É preciso proceder a uma revisão cuidadosa do atual PNE, refazendo o diagnóstico das necessidades educacionais a serem atendidas pelo sistema educacional. E esse trabalho deverá, evidentemente, ser realizado já em perfeita sintonia com os encaminhamentos relativos à construção do Sistema Nacional de Educação.

Nesse trabalho, convém tirar proveito das lições decorrentes da elaboração do plano atual. Cabe repensar a sua estrutura, concentrandose nos aspectos fundamentais e, em consequência, enxugando o texto e 
reduzindo o número de metas, seja pela aglutinação daquelas afins, seja fixando-se nos aspectos mais significativos. Isso se faz necessário para viabilizar o acompanhamento e o controle, tendo em vista, por um lado, avaliar o grau em que o plano está sendo posto em prática e, por outro, cobrar dos responsáveis o efetivo cumprimento das metas. Com efeito, há de se convir que é muito difícil para a população ter presente um conjunto de 295 metas para acompanhá-las de perto e vigiar para que sejam efetivadas.

Ao efetuar o diagnóstico e traçar as metas, será necessário tomar como referência os níveis e modalidades de ensino. Uma estratégia a ser adotada poderá ser a definição das metas gerais, deixando-se o detalhamento para ser efetuado no âmbito das instâncias do Sistema Nacional de Educação, responsáveis pela execução das referidas metas. À guisa de ilustração, tomemos o seguinte exemplo: considerando-se que todas as questôes de infraestrutura ligadas às condiçóes de funcionamento e manutenção dos prédios escolares ficarão a cargo dos municípios, definida a meta, digamos, de adequação, em até cinco anos, de todas as escolas aos padróes estabelecidos, cada município deverá detalhar, à luz de sua situação específica, os procedimentos que conduzirão ao cumprimento da meta no prazo estipulado.

Uma atenção especial deverá ser dada no PNE à questão do financiamento, não porque seja garantia da realização das metas, mas porque é condição indispensável ao seu cumprimento. Nesse aspecto, cabe considerar, à luz do que se proclama como sendo próprio da "sociedade do conhecimento", a educação como eixo do projeto de desenvolvimento do país. Assim sendo, serão destinados recursos de grande monta para equipar plenamente o Sistema Nacional de Educação. Por esse caminho, será possível duplicar imediatamente o percentual do PIB investido em educação, saltando, já em 2011, no início da vigência do novo PNE, dos atuais 4,7\% para 9,4\%. Teríamos aí um patamar para tratar, de fato, a educação com o grau de prioridade que é proclamado nos discursos. E isso é plenamente viável, porque os recursos investidos na educação não serão subtraídos da economia, mas, ao contrário, serão seu elemento propulsor, dinamizando seus diversos setores representados pela agricultura, indústria, comércio e serviços. Educação é, pois, um bem de produção e não apenas um bem de consumo.

Em síntese, aquilo que se impóe é a mudança do modelo de desenvolvimento econômico. Até agora, o modelo vem tendo por eixo o 
automóvel, o que se evidencia no fordismo, depois substituído pelo toyotismo, com todos os efeitos colaterais negativos daí decorrentes: verticalização das cidades, congestionamento do tráfego, poluição ambiental, aquecimento global, além do seu caráter concentrador da renda, com o aprofundamento das desigualdades sociais. A mudança desse eixo para a educação permitirá um desenvolvimento com maior distribuição da renda e estimulador da igualdade social e, além de não apresentar efeitos colaterais negativos, já trará consigo o antídoto aos efeitos negativos, como se constata na educação ambiental, na educação para o trânsito etc.

Complementarmente à revisão da estrutura do plano, é necessário atentar para os mecanismos a serem previstos, tendo em conta a garantia de que o plano seja, de fato, colocado em prática. A Lei n. 10.172, que instituiu o atual PNE, previu, no artigo $3^{\circ}$, avaliações periódicas, estabelecendo, no $\$ 1^{\circ}$, o acompanhamento de sua execução pelo Poder Legislativo e determinando, no $\$ 2^{\circ}$, que a primeira avaliação seria feita no quarto ano de vigência do plano. No entanto, nada disso foi feito. É importante que agora, na formulação do novo PNE, essas questões sejam devidamente equacionadas.

Uma maneira de assegurar institucionalmente o processo de acompanhamento e avaliação da execução do plano será instituir, no âmbito do Sistema Nacional de Educação, o Fórum Nacional de Educação como órgão representativo da sociedade civil do campo educacional, que deverá se reunir periodicamente, tendo como tarefa precípua o referido acompanhamento, com as atribuições de definir a política nacional de educação, as diretrizes da execução orçamentária, o Plano Nacional de Educação e, após o período de vigência do primeiro Plano Nacional de Educação, proceder à avaliação diagnóstica da sua execução, redefinindo diretrizes, prioridades e objetivos, com vistas à elaboração do novo Plano a ser executado no período subsequente. Dessa forma, o Fórum dividirá com o CNE a condição de instância máxima de deliberação e avaliação do Sistema Nacional de Educação.

Quanto à composição do Fórum, uma ideia a ser considerada seria a de que as entidades representativas da educação gozariam da prerrogativa, não de indicar representantes, mas de lançar candidatos que disputariam as vagas do Fórum em eleições amplas, cujo colégio eleitoral seria constituído por todas as pessoas envolvidas diretamente com a educação, tais como profissionais da área, professores, alunos, 
pais de alunos e funcionários das instituiçôes escolares. Seria este, talvez, um mecanismo importante de organização do campo pedagógico e de estímulo à sua mobilização e politização.

Recebido e aprovado em julho de 2010.

\section{Referências}

GRAMSCI, A. Quaderni del carcere (edizione critica dell'Istituto Gramsci a cura de Valentino Gerratana). Torino: Einaudi, 1975. 4v.

HORTA, J.S.B. Plano Nacional de Educação: da tecnocracia à participação democrática. In: CURY, C.R.J.; HORTA, J.S.B.; BRITO,V.L.A. Medo à liberdade e compromisso democrático: LDB e Plano Nacional de Educação. São Paulo: Editora do Brasil, 1997. p. 137-206.

MANIFESTO dos Pioneiros da Educação Nova: 1932. Revista Brasileira de Estudos Pedagógicos, Brasília, DF, v. 65, n. 150, p. 407-425, maio/ago. 1984.

SAVIANI, D. Educação brasileira: estrutura e sistema. 10. ed. Campinas: Autores Associados, 2008. 